\title{
Peningkatan Mutu Pendidikan Anak Usia Dini melalui Peningkatan Profesionalitas Guru
}

\author{
YUSUTRIA \\ Program Studi Pendidikan Matematika, Sekolah Tinggu Keguruan dan IImu Pendidikan \\ Persatuan Guru Republik Indonesia Sumatera Barat \\ Email: yusutriayusut@ymail.com,
}

DOI: https://doi.org/10.29313/ga.v3i1.4828

\begin{abstract}
The purpose of this study was to determine the efforts to improve the professionalism of PAUD teachers in improving the quality of Harapan Bangsa City PAUD education. Qualitative descriptive research method, while data collection techniques are based on observation, interviews, documentation. The data analysis techniques are based on data reduction, data presentation, and conclusions. PAUD institutional constraints include educational qualifications, experience, infrastructure, managers, welfare. Efforts to improve the professionalism of PAUD teachers by providing scholarships, workshops, seminars, adequate facilities, and infrastructure, as well as maintaining smooth communication with both foundations, teachers, and parents.
\end{abstract}

Keywords: Professionalism, PAUD Teachers, Quality of Education

\begin{abstract}
Abstrak
Tujuan dari penelitian ini adalah untuk mengetahui upaya meningkatkan profesionalitas guru PAUD dalam meningkatan mutu pendidikan PAUD Harapan Bangsa Kota Padang. Metode penelitian deskriptif kualitatif, sementara teknik pengumpulan data berdasarkan dengan observasi, wawancara, dokumentasi. Adapun teknik analisis data berdasarkan pada reduksi data, penyajian data dan kesimpulan. Kendala lembaga PAUD di antaranya kualifikasi pendidikan, pengalaman, sarana prasarana, pengelola, kesejahteraan. Upaya meningkatkan profesionalisme guru PAUD dengan memberikan beasiswa, workshop, seminar, fasilitas sarana prasarana yang memadai, serta tetap menjaga lancarnya komunikasi baik dengan pihak yayasan, guru, dan orang tua.
\end{abstract}

Kata Kunci: Profesionalitas, Guru PAUD, Mutu Pendidikan. 


\section{Pendahuluan}

Pembangunan nasional dalam bidang pendidikan adalah upaya mencerdaskan kehidupan bangsa dan meningkatkan kualitas sumber daya manusia Indonesia dan sangat esensial dalam membentuk manusia Indonesia (Yusutria, 2017), (Yusutria, 2018) yang beriman, bertakwa dan berakhlak mulia serta menguasai ilmu pengetahuan, teknologi, dan seni dalam mewujudkan masyarakat yang maju, adil, makmur dan beradab (UU SISDIKNAS No. 20 Tahun 2003).

Mencerdaskan kehidupan bangsa dimulai dari usia dini atau yang lebih dikenal dengan Pendidikan Anak Usia Dini (PAUD). Pendidikan anak pada usia dini memegang peranan yang sangat penting dikarenakan pada masa anak berusia 0 - 5 tahun tersebut merupakan masa emas (Setiaty, 2007).

Untuk meningkatkan mutu pendidikan pada tingkat PAUD tidak hanya melakukan pemenuhan pada aspek input dan output saja, namun yang lebih penting adalah aspek proses, yang dimaksud adalah pengambilan keputusan, pengelolaan program, proses pengelolaan kelembagaan, proses belajar mengajar dan proses monitoring dan evaluasi deengan catatan bahwa proses belajar mengajar memiliki tingkat kepentingan tertinggi dibandingkan dengan proses-proses yang lain (Aziz, 2015).

Oleh karena itu diperlukan seorang guru yang berkompeten demi menunjang mutu pendidikan tersebut. Kompetendi guru dapat dilihat dari kualifikasi pendidikannya, adapun ketentuan yang mengatur kualifikasi akademik guru PAUD menurut Peraturan Menteri Pendidikan dan Kebudayaan Republik Indonesia Nomor 137 Tahun 2014 Pasal 25 ayat 1 tentang Kualifikasi Akademik Guru PAUD:

a. Memiliki ijazah Diploma empat (D-IV) atau Sarjana (S1) dalam bidang pendidikan anak usia dini, dan kependidikan lain yang relevan dengan sistem pendidikan anak usia dini, atau psikologi yang diperoleh dariprogram studi terakreditasi, dan

b. Memiliki sertifikat Pendidikan Profesi Guru (PPG) PAUD dari perguruantinggi yang terakreditasi.
Pendidik yang melaksanakan pendidikan pada anak usia dini juga disyaratkan memiliki tingkat pendidikan dan kompetensi khusus, namun demikian pada kenyataan di lapangan masih dijumpai banyaknya tenaga pendidik PAUD yang belum memenuhi kualifikasi (Ratnaningsih, Prihatsanti, \& Prasetyo, 2015).

Rendahnya tingkat pendidikan guru PAUD mengakibatkan pula rendahnya kualitas asuhan terhadap anak usia dini, karena masih rendahnya kualitas guru/ pendidik PAUD yang belum memenuhi standar minimal yaitu untuk menjadi pendidik PAUD harus berijasah minimal setara dengan program D-4 PGTK (Pendidikan Guru Taman Kanak-Kanak) (Aprilia, 2018).

Realitanya dilapangan pendidikan bagi anak usia dini saat ini hanya diselenggarakan mengembangkan untuk kemampuan kognitifnya saja dan menjauhkan anak dari situasi budaya yang mengelilinginya. Hampir semua lembaga pendidikan anak usia dini menjadikan belajar menulis, membaca dan berhitung sebagai kegiatan inti. Orang tua dan guru seakan memaksakan harapan anak kepada anak untuk menjadi pintar secara akademik dan melupakan kodrat anak untuk tumbuh serta berkembang secara alami (Magta, 2013).

Di antara lembaga pendidikan anak usia dini (PAUD) yang ada adalah PUD Harapan Bangsa yang ada di kota Padang, yang menjadikan belajar menulis, membaca dan berhitung sebagai kegiatan inti ditambah lagi rendahnya kualitas pendidik hal tersebut berdasarkan rendahnya tingkat pendidikan guru PAUD dari 7 orang guru hanya 1 orang yang Sarjana PAUD dan 2 orang berasal dari Sarjana Pendidikan Agama Islam, 1 orang berasal dari Sarjana Pendidikan dan 2 orang tamatan Aliyah.

Oleh karena itu perlu adanya upaya untuk meningkatkan profesionalitas guru PAUD dalam meningkatan mutu pendidikan PAUD Harapan Bangsa Kota Padang. Tujuan dari penelitian ini adalah untuk mengetahui upaya meningkatkan profesionalitas guru PAUD dalam meningkatan mutu pendidikan PAUD Harapan Bangsa Kota Padang. 


\section{Metodologi Penelitian}

Penelitian ini menggunakan metode penelitian deskriptif kualitatif, dengan menggambarkan suatu gejala sosial yang memerlukan ketajaman analisis, objektifitas, sistematik dan sistemik sehingga diperoleh ketepatan dalam interprestasi berdasarkan mutu dengan cara mendeskripsikan data dan fakta melalui kata-kata secara menyeluruh terhadap subjek penelitian (Margono, 2004), (Sugiyono, 2008), (Mulyana, 2008), (Sukardi, 2013).

Teknik pengumpulan data berdasarkan dengan observasi, wawancara, dokumentasi. Adapun teknik analisis data berdasarkan pada reduksi data, penyajian data dan kesimpulan.

\section{Tinjuan Pustaka \\ Guru PAUD}

Lembaga PAUD perlu kiranya sosok guru yang memiliki kualifikasi, kompentensi dan dedikasi dalam melaksanakan tugas keprofesionalannya sebagai pendidik (Karmila, 2017), (Hasmah, 2017).

Pendidik merupakan sebutan untuk seseorang yang berprofesi sebagai pendidik (Munandir, 2001) atau orang yang mendidik (Setiawan, 2014). Dalam konteks penelitian ini yang dimaksudkan sebagai pendidik adalah guru Pendidikan Anak Usia Dini (PAUD). Guru PAUD yang dimaksud adalah PAUD formal yang terdiri dari TK/RA (PP. 19/2005: pasal 30: 1). Menurut Permendiknas Nomor 58 Tahun 2009 Tentang Standar Pendidikan Anak Usia Dini, disebutkan bahwa pendidik anak usia dini adalah profesional yang ber tugas, melaksanakan proses pembelajaran, dan menilai hasil pembelajaran serta melakukan pembimbingan, pengasuhan, dan perlindungan anak didik. Guru PAUD dipersyaratkan memiliki kualif ikasi dan kompetensi (Arifin \& Fardana, 2014).

Pekerjaan guru adalah salah satu bidang pekerjaan yang terkait langsung dengan kebutuhan masyarakat. Oleh karena itu bilamana masyarakat semakin kritis mengamati dan menilai keberhasilan dan kegagalan tugas guru adalah sesuatu yang lumrah. Guru merupakan 'the front linear' nya berbagai upaya peningkatan mutu pendidikan nasional (Sa'ud, 2000:35).
Demikian pula guru merupakan salah satu faktor penentu keberhasilan atau kegagalan upaya-upaya peningkatan mutu dan inovasi pendidikan di tingkat sekolah (Fullan, 1992; Goodlad, 1990).

Terlebih lagi saat ini masyarakat, utamanya para orang tua sangat berkepentingan dengan layanan pendidikan yang berkualitas, dan sebagian besar tanggung jawab terdepan untuk mewujudkan harapan dan cita-cita tersebut memang berada di pundak guru (Marienda, $\mathrm{H}$, 1994)

Guru PAUD beperan penting dalam pengembangan karakter siswa atau anak didik yang nantinya merupakan generasi penerus bangsa (Hariyanti, 2012) (Rahayu, 2015). Dalam Peraturan Menteri Pendidikan Nasional Republik Indonesia nomor 16 Tahun 2007 standar kompetensi guru PAUD/TK/RA menyebutkan tentang kompetensi profesional sebagai berikut yakni: (1) Menguasai materi, struktur, konsep dan pola pikir keilmuan yang mendukung mata pelajaran yang diampu, (2) Menguasai standar kompetensi dan kompetensi dasar mata pelajaran/bidang pengembangan yang diampu, (3) Mengembangakan materi pembelajaran yang diampu secara kreatif, (4) Mengembangakan keprfesionalan secara berkelanjutan dengan melakukan tindakan reflektif, dan (5) Memanfaatkan teknologi informasi dan komunikasi untuk berkomunikasi dan mengembangkan diri.

Peran guru sebagai pemberi inspirasi belajar (to giving learning inspiration), mempersyaratkan guru untuk mampu memerankan diri sebagai sosok yang memberikan inspirasi pembelajaran bagi peserta didik (inspiring teaching for student), sehingga kegiatan belajar dan pembelajaran dapat membangkitkan berbagai pemikiran, imajinasi, kreativitas, gagasan, dan ide-ide baru (Arifin \& Fardana, 2014), (Mulyasa, 2007; Arifin, 2010).

Selain dalam konteks pembelajaran maka guru harus mampu memberikan contoh yang baik dalam hidup dan berbudaya (uswatun hasanah). Guru harus mampu membangkitkan kebesaran diri peserta didiknya dengan memiliki kebesaran 
diri atau rasa percaya diri (self confident) tersebut (Arifin \& Fardana, 2014).

\section{Hakikat Pembelajaran Anak Usia Dini}

Menurut Haenilah (2015) ada beberapa karakteristik belajar yang harus dipahami oleh guru di antaranya adalah 1) anak hanya bisa belajar jika tidak dipisahkan dari kebutuhan bermainnya, 2) anak hanya bisa belajar jika dalam bermainnya dibantu oleh alat permainan secara kongkrit, 3) anak hanya bisa belajar jika perannya terlindungi, 4) anak hanya bisa belajar jika terbebas dari paksaan orang dewasa.

Pendidikan anak usia dini pada hakikatnya adalah pendidikan yang diselenggarakan dengan tujuan memfasilitasi pertumbuhan dan perkembangan anak secara menyeluruh atau menekankan pada pengembangan seluruh aspek kepribadian anak (Hidayah, 2013).

\section{Kompetensi Guru}

Menurut Uzer Usman (2006), bahwa kompetensi (competency), yakni kemampuan atau kecapan, yang harus dimiliki seorang guru yaitu, (1) kemampuan yang ada pada diri guru agar dapat mengembangkan kondisi belajar sehingga hasil belajar dapat tercapai dengan efektif, (2) kemampuan sosial yaitu kemampuan guru yang realisasinya memberi manfaat bagi pemenuhan yang diperuntukan bagi masyarakat, (3) kompetensi profesional adalah kemampuan yang dimilliki guru sebagai pengajar yang baik. Dan pada (4) kompetensi kepribadian.

Syaiful Jamarah (2000 : 40) mengatakan, kepribadian adalah keseluruhan dari individu yang terdiri dari unsur psikis dan fisik. Kepribadian dapat menentukan apakah guru menjadi pendidik dan pembina yang baik atau penghancur bagi hari depan anak didik, terutama bagi anak didik yang masih kecil, usia dini (tingkat sekolah dasar) dan yang sedang mengalami kegoncangan jiwa (tingkat remaja). (Darmayanti, 2006)

Adapun kompetensi yang harus dimiliki seorang pendidik agar mampu dan cakap, tingkahlaku dalam mengerjakan suatu pekerjaan khususnya bidang pendidikan, (Moh. User Usman, 2002), (Abd. Rahman Getteng, 2014), terdapat dalam PERMENDIKBUD RI No. 137 Tahun 2014 tentang Standar Nasional Pendidikan Anak Usia Dini Pasal 25 dan juga dalam Undang-Undang No. 14 Tahun 2005 Tentang Guru dan Dosen pasal 10 dijelaskan tentang: "Kompetensi guru PAUD dikembangkan secara utuh mencakup kompetensi pedagogik, kepribadian, sosial, dan profesional, sebagaimana terdapat pada lampiran II yang merupakan bagian tidak terpisahkan dari PeraturanMenteri ini".

Kompetensi tersebut terdapat ilmu-ilmu untuk mengelola pembelajaran seperti modelmodel pembelajaran, pendekatan pembelajaran dan desain pembelajaran sehingga dapat memudahkan ketercapaian dari tujuan pembelajaran itu sendiri (Hamzah B. Uno, 2009).

\section{Hasil dan Pembahasan Kendala yang dihadapi oleh lembaga PAUD

\begin{tabular}{cl}
\hline No & \multicolumn{1}{c}{ Kendala } \\
\hline 1 & Kualifikasi pendidikan guru \\
\hline 2 & Pengalaman mendidik \\
\hline 3 & Sarana prasarana \\
\hline 4 & Pengelolaan secara swasta \\
\hline 5 & Kesejahteraan masih relatif kecil \\
\hline
\end{tabular}

Kendala-Kendala yang dihadapi oleh lembaga pendidikan anak usia dini Harapan Bangsa dalam pelaksanaan pendidikan anak usia dini masih terdapat kendala-kendala yang perlu dihadapi dan dicarikan solusinya secara bersama-sama, di antaranya:

a. Masih terdapat guru-guru PAUD yang belum memenuhi kualifikasi akademik. Sebagian besar guru PAUD. Hal ini sesuai dengan observasi bahwa dari 7 orang guru hanya 1 orang yang Sarjana PAUD dan 2 orang berasal dari Sarjana Pendidikan Agama Islam, 1 orang berasal dari Sarjana Pendidikan dan 2 orang tamatan Aliyah. Sehingga menjadi sedikit penghambat dalam peningkatan kualitas pendidikan anak usia dini.

b. Sarana dan prasarana masih terbatas dan belum memenuhi standar ideal pendidikan anak usia dini.

c. Lembaga PAUD di dikelola oleh swasta, 
sehingga pembiayaan operasional seharihari masih sangat terbatas.

d. Kesejahteraan guru PAUD di masih relatif kecil, sehingga secara tidak langsung berpengaruh terhadap layanan dan proses pembelajaran pendidikan anak usia dini (Fadlillah, 2018).

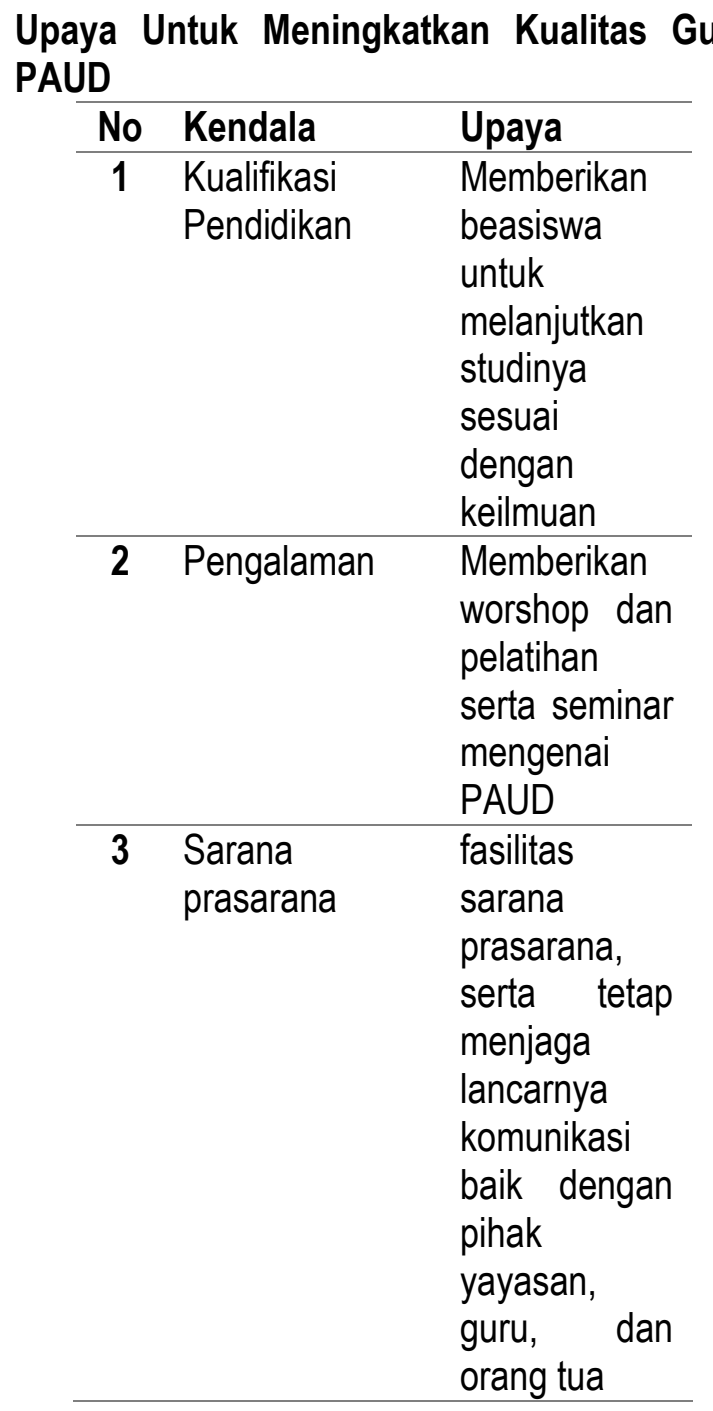

Upaya dalam meningkatkan kualitas pendidikan melalui sumber daya manusia, salah satunya yaitu faktor tenaga pendidik atau guru yang memiliki andil cukup besar dalam meningkatkan kualitas pendidikan itu sendiri. Ini dikarenakan guru bertindak sebagai agen pembelajaran dan langsung bertatap muka serta berinteraksi dengan siswa. Oleh karena itu perlu diadakan pembinaan berupa pelatihan, seminar, atau workshop dengan tujuan meningkatkan kualitas guru untuk lebih memahami bagaimana mengoptimalkan siswa di sekolah (Erviana, n.d.)

Berdasarkan penelitian yang telah dilakukan menunjukkan bahwa: (a) Kemampuan guru yang semakin mumpuni dalam menghadapi siswa, pengetahuan dan keterampilan guru semakin meningkat. (b) Meningkatkan KBM dikelas. (c) Orang tua sebagai konsumen pendidikan juga merasakan hasilnya. Terbukti dengan perkembangan anak semakin membaik, kemandirian anak meningkat, dan sedikit demi sedikit mampu mengatasi kebutuhan khususnya. (d) Dalam menjaga kualitas guru yang ada kepala sekolah melakukan kontrol, pengawasan kinerja, pantauan secara rutin, mengupdate perkembangan terbaru, memberikan reward pada guru dan lainnya. (e) Kepala sekolah juga memperhatikan masukan dari guru yang menginginkan adanya pelatihan emosional dan meningkatkan fasilitas sarana prasarana, serta tetap menjaga lancarnya komunikasi baik dengan pihak yayasan, guru, dan orang tua.

Pelaksanaan pendidikan anak usia dini dilihat melalui beberapa unsur, di antaranya: kurikulum, model pembelajaran, sarana dan prasarana. (Fadlillah, 2018), (Sudarwan Danim, 2003). Hal tersebut sesuai bahwa untuk meningkatkan mutu pendidikan yaitu: 1) Kecakupan sumber-sumber pendidikan dalam arti mutu tenaga pendidikan, biaya, sarana belajar. 2) Mutu proses belajar yang mendorong siswa belajar efektif. 3) Mutu keluaran dalam bentuk pengetahuan, sikap, keterampilan, dan nilai-nilai.(Hasmah, 2017), (Nanang Fattah, 2000).

\section{Kesimpulan}

Kendala yang dihadapi oleh pengelola lembaga PAUD di antaranya kualifikasi pendidikan, pengalaman, sarana prasarana, pengelola, kesejahteraan. Adapun upaya yang dilakukan dalam meningkatkan profesionalisme guru PAUD yaitu diperlukannya bantuan beasiswa kepada para guru PAUD, workshop, seminar, fasilitas sarana prasarana yang memadai, serta tetap menjaga lancarnya komunikasi baik dengan pihak yayasan, guru, dan orang tua. 


\section{Daftar Pustaka}

Aprilia, D. (2018). Hubungan Kualifikasi Guru Dengan Pemahaman Mengelola Pembelajaran Anak Usia Dini Di Kecamatan Metro Utara. Fakultas Keguruan Dan IImu Pendidikan Universitas Lampung.

Arifin, A. K., \& Fardana, N. A. (2014). Peran Pendidik PAUD dalam Mengimplementasikan Pendidikan Karakter Melalui Metode Pembelajaran Sentra dan Lingkaran. Jurnal Psikologi Pendidikan Dan Perkembangan, 3(3), 188-198.

Aziz, A. (2015). Peningkatan Mutu Pendidikan. Jurnal Studi Islam, 10(2), 1-13.

Darmayanti, M. Z. N. N. (2011). Pengaruh Latar Belakang Pendidikan Dan Masa Kerja Terhadap Kinerja Guru Raudhatul Athfal Di Medan. Jurnal Analitika, Vol 3, No. 1, 3744.

Erviana, S. (n.d.). Upaya Kepala Sekolah Dalam Meningkatkan Kualitas Guru Di Paud Inklusi Pelangiku Jombang. Jurnal Inspirasi Manajemen Pendidikan, Vol. IV, No. 1, 1-6.

Fadlillah, M. (2018). Persepsi Mahasiswa PGPAUD Universitas Muhammadiyah Ponorogo terhadap PAUD di Kabupaten Ponorogo. Jurnal Obsesi : Jurnal Pendidikan Anak Usia Dini, 2(1), 118-123.

Hasmah. (2017). Pengaruh Kompetensi Tenaga Pendidik Terhadap Peningkatan Mutu Pendidikan Di Smp Negeri 5 Duampanua Kabupaten Pinrang. Universitas Islam Negeri Alauddin Makassar.

Hidayah, R. N. (2015). Pendidikan Anak Usia Dini Perspektif Ki Hajar Dewantara. EjournallAINNgawi

Kamila, I. N. (2017). Perbedaan Kinerja Mengajar Guru Pendidikan Anak. Tunas Siliwangi, 3(1), 38-56.

Magta, M. (2013). Konsep Pendidikan Ki Hajar Dewantara Pada Anak Usia Dini. Jurnal pendidikan usia dini, 7(2), 221-232.

Marienda, W., \& H, E. N. (2015). Kompetensi dan profesionalisme guru pendidikan anak usia dini. Jurnal Unpad. Prosiding Penelitian \& Pengabdian Kepada Masyarakat. Vo. 2, No. 2, 147-156.
Peraturan Menteri Pendidikan Nasional Republik Indonesia nomor 16 Tahun 2007.

PERMENDIKBUD RI No. 137 Tahun 2014 tentang Standar Nasional Pendidikan Anak Usia Dini Pasal 25.

Peraturan Menteri Pendidikan dan Kebudayaan Republik Indonesia Nomor 137 Tahun 2014.

RAHAYU, N. (2015). Peningkatan Mutu Pendidikan Di Pendidikan Anak Usia Dini ( PAUD ) Fatimah Desa Purbayan. Program Pascasarjana Institut Agama Islam Negeri Surakarta.

Ratnaningsih, I. Z., Prihatsanti, U., \& Prasetyo, A. R. (2015). Pelatihan Bagi Kader Pendidikan Anak Usia Dini ( PAUD ) Kecamatan Banyumanik Semarang. INFO, XVII(2), 97110.

Setiaty, M. S. Y. T. (2007). Kompetensi Pedagogik Guru Paud Dalam Mengembangkan Pembelajaran Untuk Anak Usia Dini. Cakrawala Dini, Jurnal Pendidikan Anak Usia Dini, Vol 3 No. 1, (23).

UU SISDIKNAS No. 20 Tahun 2003.

Undang-Undang No. 14 Tahun 2005 Tentang Guru dan Dosen.

Yusutria. (2017). Profesionalisme Guru Dalam Meningkatkan Kualitas Sumberdaya Manusia. Jurnal Curricula, 2(2), 38-46. https://doi.org/10.1007/s10096-009-0783-8

Yusutria. (2018). Analisis Mutu Lembaga Pendidikan Berdasarkan Fungsi Manajemen Di Pondok Pesantren Thawalib Padang Sumatera Barat. Ta'dib: Jurnal Pendidikan Islam, VII(2), 84-95. 